\title{
A proliferação de memoriais às vítimas no Brasil: Reflexões em torno a alguns casos recentes
}

\author{
La proliferación de memoriales a las víctimas en el Brasil: Reflexiones en \\ torno algunos casos recientes
}

The proliferation of memorials to victims in Brazil: Reflections on some

\author{
recent cases
}

\author{
Danilo Amparo Rangel ${ }^{1}$ \\ Carolina Gomes Nogueira ${ }^{2}$ \\ Virginia Susana Vecchiolli ${ }^{3}$ \\ Juliane Conceição Primon Serres ${ }^{4}$
}

\begin{abstract}
Resumo
O presente artigo trata sobre a criação de espaços memoriais dedicados às vítimas no Brasil na última década (2008-2018) a partir de três recortes: a) os memoriais voltados à ditadura militar brasileira (1964-1985), b) os memoriais às vítimas de acidentes aéreos (2007) e c) os ligados ao incêndio de um local noturno (2013). Encontrando nestas ações memoriais, decorrentes de acontecimentos traumáticos, como fenômeno de 'proliferação' da memória, através do qual ações memoriais que partem de grupos diversos de atores que reivindicam o não esquecimento de suas vítimas e dos crimes cometidos. Desta forma, possibilitando a marcação de territórios não mais somente pela ação e iniciativa do Estado, mas também em confluência entre estes grupos de vítimas, sobreviventes, familiares e outros vinculados a estes. Nossa proposta busca saber quem são os atores que compõe a rede de criação destes espaços e como estes desenvolvem as narrativas, buscam recursos e ressignificam esses locais. Nesse sentido, compreendemos que a depender dos tipos de agentes envolvidos nos processos de constituição de memoriais, estes vão definir a forma como serão conduzidos o planejamento, execução e manutenção, entre outras características destes espaços. O trabalho desenvolve-se por meio de pesquisa documental em periódicos e sites das iniciativas. Esta pesquisa vem sendo realizada com apoio da FAPERGS.
\end{abstract}

Palavras-chaves: Memoriais; Memória; Vítimas.

\section{Resumen}

El presente artículo trata de la creación de espacios memoriales dedicados a víctimas del Brasil en la última década (2008-2018). Son los recortes, a) memoriales de la dictadura militar brasileña (1964-1985), b) los memoriales a las víctimas de accidentes aéreos (2007) y los victimados de lo incendio en una casa nocturna (2013). Las mencionadas acciones memoriales, decurrentes de acontecimientos de trauma, vistos como fenómeno de proliferación de la memoria, por lo cual acciones memoriales parten de diversos grupos de actores que llaman por justicia y para no olvidar sus víctimas y los crímenes cometidos. De esta manera, haciendo marcas en los territorios ahora también por acción o iniciativa de los grupos de víctimas y familiares y no únicamente por el Estado, siendo un proceso de confluencia. Nuestra pesquisa busca investigar quiénes son los actores que componen a la red de creación de estos espacios y cómo se desarrollan las narrativas, buscan recursos y resignifican estos locales. En

\footnotetext{
${ }^{1}$ Graduando em Museologia; Universidade Federal de Pelotas - FAPERGS; Pelotas, Rio Grande do Sul, Brasil; drangeldanilo@gmail.com.

${ }^{2}$ Graduanda em Museologia; UFPel - CNPq; Pelotas, Rio Grande do Sul, Brasil; nogueiracarolina1996@gmail.com.

${ }^{3}$ Pós-doutora; UFSM - PPGSOCIAIS; Santa Maria, Rio Grande do Sul, Brasil; virginiavechiolli@gmail.com.

${ }^{4}$ Doutora; UFPel - PPGMP; Pelotas, Rio Grande do Sul, Brasil; julianeserres@gmail.com.
} 
este sentido suponemos que los agentes envueltos en los procesos definen la manera como ellos son desarrollados. La investigación es realizada con pesquisa documental y en los sitios de las iniciativas. La investigación contó con el apoyo de la fundación del apoyo a pesquisa del Rio Grande del Sur.

Palabras claves: Memoriales; Memoria; Víctima.

\begin{abstract}
The present article deals with the creation of memory spaces dedicated to victims in Brazil in the last decade (20082018) from three cuts: a) the memorials to the Brazilian military dictatorship (1964-1985), b) the memorials to the victims of air accidents (2007) and c) those associated with the burning of a night spot (2013). Finding in these memorable actions, resulting from traumatic events, as a phenomenon of 'proliferation' of memory, through which memory actions that depart from diverse groups of actors who claim not to forget their victims and crimes committed. In this way, allowing the marking of territories not only by the action and initiative of the State, but also in confluence between these groups of victims, survivors, relatives and others linked to them. Our proposal seeks to know who are the actors that make up the network of creation of these spaces and how they develop the narratives, look for resources and resignify these places. In this sense, we understand that depending on the types of agents involved in the processes of constitution of memorials, these will define how the planning, execution and maintenance will be conducted, among other characteristics of these spaces. The work is developed through documentary research in periodicals and initiatives websites. This research has been carried out with the support of FAPERGS.
\end{abstract}

Keywords: Memorials; Memory; Victims.

\title{
1. Introdução
}

A criação de memoriais dedicados às vítimas no Brasil é uma prática complexa que envolve dimensões múltiplas, a instituição de lugares políticos, a reivindicação por justiça, memória e luto. Os memoriais que neste artigo são descritos como espaços decorrentes de memórias percebidas como traumáticas. Abordaremos especificamente três memoriais: o Memorial da Resistência de São Paulo, um espaço dedicado à preservação da memória de vítimas da ditadura militar que constitui também um lugar que denuncia a atos de repressão, tortura e violação dos direitos humanos; o Memorial 17 de julho e o Memorial Largo da Vida dedicados a preservação da memória de 199 pessoas que morreram no voo 3054 da empresa TAM em 2007; e os Memoriais às Vítimas da boate Kiss, dedicado à memória de 242 pessoas que foram vitimadas em 2013 após de um incêndio.

Pensando na criação de memoriais, diversos são os motivos e atores que conduzem suas criações, nos casos que aqui serão citados podemos perceber desde a intervenção de ação política de algumas instâncias vinculadas aos acontecimentos, a mediações por parte de expertos, e a resistências daqueles que sentiram na pele os traumas. Oriundo das mais diversificadas ações surgem diversos patrimônios resultado dos desejos daqueles que detém o poder ou por aqueles que resistem, assim menciona Fabri, que se criam redes que serão responsáveis pela ativação da memória (FABRI, 2013). 
Nossa proposta busca saber quem são os atores que compõe a rede de criação destes espaços e como estes desenvolvem as narrativas, buscam recursos e ressignificam esses locais (POLLAK, 1989). Nesse sentido, compreendemos que a depender dos tipos de agentes envolvidos nos processos de constituição de memoriais, estes vão definir a forma como serão conduzidos o planejamento, execução e manutenção, entre outras características destes espaços.

Nossa abordagem comparativa vai nos permitir identificar semelhanças e diferenças entre os processos que levaram a criação dos três memoriais que serão objeto desta análise, são eles o Memorial da Resistência em São Paulo, o Memorial 17 de julho na mesma cidade, o Memorial Largo da Vida em Porto Alegre, e os Memoriais às vítimas da boate Kiss.

\section{Memorial da Resistência de São Paulo}

Na história do Brasil registram-se dois períodos autoritários, o primeiro de 1930-1945 caracterizado como Estado Novo, implementado por Getúlio Vargas durante a sua presidência, e o segundo período denominado regime militar marcado por um golpe de estado contra o governo democrático de João Goulart em 1964 que vigorou até 1984 (BRITO, 2014).

O Memorial da Resistência de São Paulo é uma instituição que integra a Secretaria de Cultura do Governo do Estado de São Paulo. Essa instituição é uma das poucas que visa trabalhar a memória do período ditatorial no Brasil, foi inaugurada em 29 de janeiro de 2009. É dedicada à preservação de referências das memórias da resistência e da repressão política do Brasil e está localizado no prédio que foi sede, do Departamento Estadual de Ordem Política e Social de São Paulo (DEOPS-SP) durante o período de 1940 a 1983. O DEOPS foi criado em 1935 com o objetivo de perseguir "comunistas" e passou a funcionar depois de que ele fosse aprovado pela Assembleia Legislativa (LUNA, 2007, 22 apud BRITO, 2014).

Hoje em dia ele está vinculado à esfera transnacional integrando a Coalizão Internacional de Sítios de Consciência (Sites of Conscience) rede mundial que agrega lugares destinados a preservação das memórias de eventos pela luta da justiça.

Em seu programa de expografia, o Memorial conta com duas exposições, a de longa duração está voltada para o histórico do edifício e seus respectivos desdobramentos de controle, repressão e resistência, e as temporárias que contam com argumentos extraídos da exposição de longa duração. A exposição de longa duração se dividiu em quatro módulos, sendo: Módulo A - o edifício e suas memórias; Módulo B - Controle, repressão e resistência: o tempo político e a memória; Módulo C - A construção da memória: o cotidiano nas celas do DEOPS/SP e Módulo D - Da carceragem ao Centro de Referência. 
O projeto expográfico do Memorial da Resistência de São Paulo contou com a participação do Fórum Permanente dos ex-presos e perseguidos políticos do Estado de São Paulo, e foi através das memórias dos ex-presos e perseguidos políticos que foi realizada a concepção do espaço museológico. O Fórum é uma Associação Privada do Estado de São Paulo surgida em 30 de outubro de 2001, a fim de promover a defesa dos direitos humanos. De acordo com seu regulamento:

Artigo $2^{\circ}$ - O Fórum Permanente dos Ex-Presos e Perseguidos Políticos têm por objetivo social: 1- A promoção de Direitos Estabelecidos, construção de Novos Direitos e assessoria jurídica gratuita de interesse suplementar aos Ex-Presos e Perseguidos Políticos; 2- A promoção da Ética, da Paz, da Cidadania, dos Direitos Humanos, da Democracia, a Unidade na Propositura de Ações e outros valores humanos universais; 3- A Promoção da Cultura, Defesa e Conservação do Patrimônio Histórico e Cultural dos valores almejados pelos Ex-Presos e Perseguidos Políticos; 4- A produção e divulgação de informações e conhecimentos, estudos e pesquisa relacionados aos Ex-Presos e Perseguidos Políticos; (Reformulação do estatuto do fórum dos ex-presos e perseguidos políticos do Estado de São Paulo, 2 de março de 2013)

O Fórum foi constituído por aqueles que no presente se reconhecem como Ex-presos, Banidos, Exilados, Refugiados e Perseguido Político das Ditaduras Militares no Brasil.

Na própria expografia do memorial, uma sala é dedicada a relatar o processo de ação entre especialistas e não especialistas, em diversos encontros que visavam o compartilhamento das memórias difíceis dos ex-presos políticos com a equipe responsável pela curadoria do memorial, conforme a figura 1.

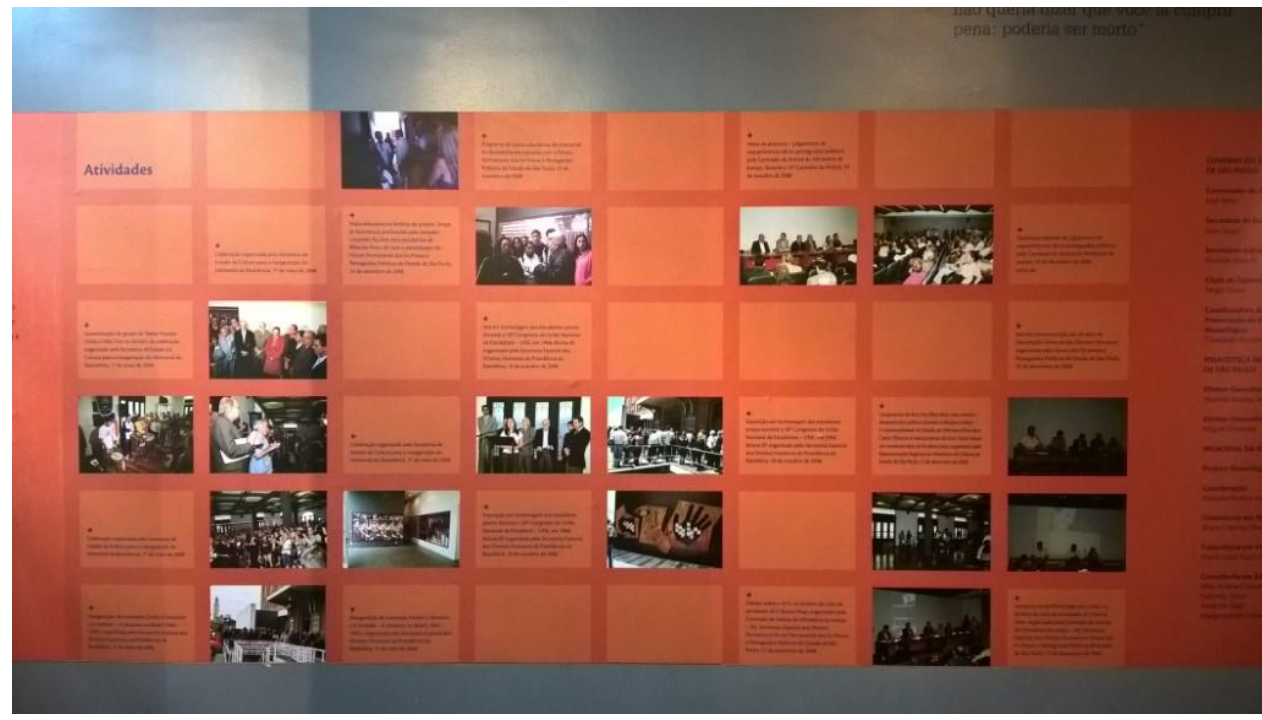

Figura 1: Mural atividades de criação e ação no Memorial da Resistência.

Fonte: Autores

\section{Memoriais às vítimas do voo da Tam 3054}


No dia 17 de julho de 2007, ao final da tarde, decola do aeroporto Salgado Filho em Porto Alegre, capital do Rio Grande do Sul, o voo 3057 da Tam Linhas Aéreas brasileiras $\mathrm{SA}^{2}$ com destino ao aeroporto de Congonhas em São Paulo. Na hora de aterrissar o avião toca o solo da pista que estava molhada, perde o rumo, atravessa uma avenida e bate contra um prédio da própria TAM, produzindo a morte de 199 pessoas, sendo 181 passageiros, 6 tripulantes ativos, e 12 em terra ${ }^{3}$.

Após o acontecimento familiares das vítimas se reúnem e anunciam em 16 de setembro de 2007 a criação da Associação dos Familiares e Amigos das Vítimas do Voo TAM JJ 3054 (AFAVITAM), com o intuito de articular com a empresa aérea e com o ministério público a assistência a ser prestada para os familiares, a transparência quanto às investigações e a reparação por meio de indenizações.

\section{Memorial 17 de julho}

Nove dias após a considerada maior tragédia da aviação brasileira, a prefeitura da cidade de São Paulo, na figura do Prefeito já anunciava a demolição do prédio da Tam para a semana seguinte argumentando que ele se encontrava em risco de desabamento. Neste momento, conforme veicula o Extra ${ }^{4}$ o poder Executivo empreendia tratativas com a dona do terreno para seu uso como espaço em memória às vítimas do acontecimento.

Logo da execução da demolição do prédio, a Tam anuncia a doação do espaço para o município $^{5}$, por isso confirma-se a construção do memorial. Contudo, somente no ano de 2011, a partir da assinatura de um protocolo de intenções entre a Prefeitura e a Associação de Familiares e Amigos das Vítimas do voo TAM JJ 3054 (AFAVITAM), o prefeito reeleito anuncia que o memorial será inaugurado em 2012, ano em que se completa cinco anos da tragédia. Junto a isso, em seu anúncio público divulga que o projeto buscou atender as

\footnotetext{
2 Após junção com a Chilena Lan Airlines passa a chamar-se Latam Airlines (2012).

3 Conforme o relatório final A- nº 67/2009 do Centro de Investigação e Prevenção de Acidentes Aeronáuticos (CENIPA), sob administração do Comando da Aeronáutica, divulgado em 2009

4 Extra, Prefeitura anuncia demolição do prédio da TAM Express para este domingo, (2007), disponível em https://extra.globo.com/noticias/brasil/prefeituraanuncia-demolicao-do-predio-da-tam-express-para-este-domingo-692726.html. Acessado em 16 de novembro de 2018.

5 TERRA, Prédio da TAM Express é implodido sob aplausos, disponível em http://noticias.terra.com.br/brasil/acidentecongonhas/interna/0,,OI1810207EI10210,00-Predio+da+TAM+Express+e+implodido+sob+aplausos.html. Acessado em 16 de novembro de 2018.
} 
expectativas dos familiares das vítimas e da cidade de São Paulo ${ }^{6}$. Sendo suprimida a menção realizada em 2010, a escola técnica AFAVITAM a ser construída na cidade de São Paulo ${ }^{7}$.

O projeto do memorial é do arquiteto Marcos Cartum contratado pela administração municipal. Seu projeto, constrói-se no entorno da única sobrevivente, uma árvore, e diz “A árvore foi convertida no projeto como um elemento simbólico principal. Tudo é circular em torno da árvore. É um lugar de memória e de celebração à vida, um espaço de convivência, de lazer." 8

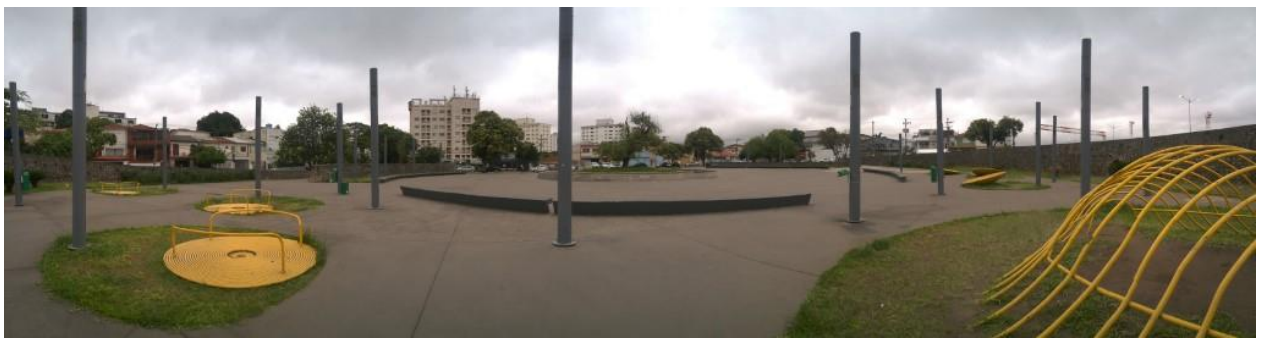

Figura 2: Foto panorâmica da Praça 17 de julho.

Fonte: Autores

Assim,

[...] o Memorial 17 de Julho tem 8,3 mil metros quadrados e fica na frente da cabeceira da pista de Congonhas. As obras duraram sete meses e custaram R \$ 3,6 milhões. O prefeito Gilberto Kassab (PSD) foi à cerimônia. "É um local de homenagem e um local de alerta. Espero que todas as autoridades que passam por aqui e são responsáveis pela aviação civil coloquem as mãos à obra", disse o prefeito, em referência à melhoria da segurança aérea. (ESTADÃO, 17.07.12)

O elemento central da praça é o espelho d'água que circunda a árvore que sobreviveu ao impacto e ao incêndio do prédio. A estrutura circular recebeu o nome das 199 vítimas, bem como uma estrela amarela provisória confeccionada em material plástico, até receber as definitivas em aço. Na figura 3 é possível visualizar o nome de algumas vítimas e o estado de conservação do monumento.

6 G1, Memorial para vítimas de acidente da TAM fica pronto em 1 ano, diz Kassab (2011), disponível em http://g1.globo.com/sao-paulo/noticia/2011/07/memorialpara-vitimas-de-acidente-da-tam-fica-pronto-em-1-ano-diz-kassab.html. Acessado em 16 de novembro de 2018.

erno=0\&Noticia $=189437$. Acessado em 16 de novembro de 2018.

7 Correio do Povo (2010), Afavitam planeja Memorial 17 de Julho em SP, disponível em http://www.correiodopovo.com.br/Impresso/?Ano=115\&Numero=334\&Caderno=0\&Noticia=189437. Acessado em 16 de novembro de 2018 .

8 IG, Praça em homenagem às vitimas da TAM pode crescer, (2017), disponível em https://ultimosegundo.ig.com.br/desastresaereos/praca-em-homenagem-asvitimas-da-tam-pode-crescer/n1597086565519.html. Acessado em 16 de novembro de 2018. 


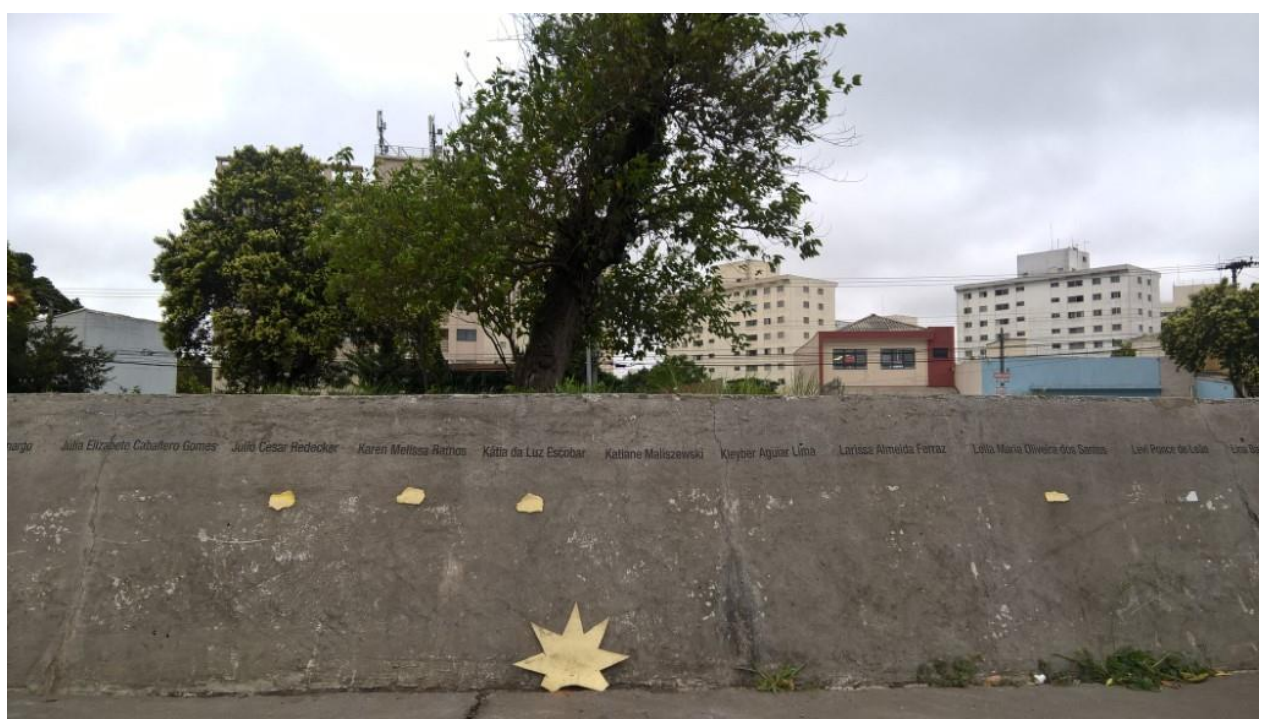

Figura 3: Recorte da estrutura do espelho d'água com nomes de vítimas.

Fonte: Autores

\section{Memorial Largo da Vida}

Uma outra iniciativa vinculada ao voo 3054 surge na cidade de Porto Alegre. O largo da vida foi uma iniciativa simbólica protagonizada pelos familiares, que em 2008 elegeram um espaço para ser representação da memória às vítimas. Na época plantaram 199 árvores no espaço da Avenida Severo Dullius em Porto Alegre, próximo ao Aeroporto Salgado Filho. Assim, elegendo a rótulo desta avenida como Largo da Vida, a ser um local de homenagem às vítimas e de proposição para a construção de um memorial, que segundo o Presidente da AFAVITAM, será uma escultura com 199 estrelas em forma de espiral. A ser executada pelo artista Carlos Tenius, sendo necessário o investimento estimado de em $\mathrm{R} \$ 1$ milhão a ser buscado na prefeitura da cidade ${ }^{9}$. Até o presente momento, nenhuma estrutura foi construída no local, que é utilizado por familiares e amigos como base para as ações em homenagem a cada aniversário da tragédia.

Neste caso, o local que representa a tragédia, foi transformado em uma praça memorial, além da marcação de outro local na cidade de Porto Alegre. Os dois casos, São Paulo e Porto Alegre são desenvolvidos a partir de diferentes iniciativas e atores. Sendo o primeiro conduzido pelos cuidados da prefeitura, e o segundo por iniciativas próprias dos familiares das vítimas que residiam no Rio Grande do Sul.

9 Correio do Povo, (2012), disponível em http://www.correiodopovo.com.br/Noticias/Geral/2012/7/444578/Atos-na-Capital-pedem-punicao-e-lembram-acidente-da-TAM. Acessado em 16 de novembro de 2018. 


\section{Santa Maria e a boate Kiss}

A cidade localiza-se no centro-oeste do estado do Rio Grande do Sul, é cercada por montes que configuram a característica própria da região, estes deram origem ao nome Santa Maria da Boca do Monte. Distante cerca de 290 km da capital do Estado, Porto Alegre, é uma cidade de porte médio, com 280.505 habitantes segundo estimativa do IBGE (2018) em um território de $1.781,757 \mathrm{~km}^{2}{ }^{10}$.

Santa Maria é conhecida como uma cidade universitária, tendo como maiores instituições a Universidade Federal de Santa Maria, criada por meio do decreto lei 3.834-C de 1960, contando no ano de 2018 com 25.569 alunos em 265 cursos $^{11}$ e com a Universidade Franciscana, fundada em 1955, atualmente com 6.400 alunos em 72 cursos $^{12}$, entre outras instituições de ensino superior da cidade.

Por isso, os santa-marienses costumavam dizer que era uma cidade alegre, viva e movimentada, aplicando isso também a cena noturna, em que centenas de jovens estudantes protagonizaram nos mais diversos espaços, como a tão conhecida por aqueles que por lá passaram, boate do DCE da UFSM, ou mesmo a badalada Kiss.

A boate Kiss, Santo Entretenimento Ltda. foi uma casa noturna localizada no centro do município de Santa Maria, na Rua dos Andradas, 1925. Suas atividades tiveram início no ano de 2009 e encerraram-se fatidicamente em 2013, com um incêndio que usurpou a vida de 242 pessoas. A boate tinha uma área total de $615 \mathrm{~m}^{2}$, era composta por dois ambientes, cada um com um palco, além disso, pelo ambiente dispunham-se bares, um mezanino e uma única porta para entrada e para saída. A capacidade anunciada pelos proprietários era de 1000 pessoas $^{13}$.

O cenário do acontecimento remete a noite de sábado e madrugada de domingo (26/27) do mês de janeiro do ano de 2013, durante a festa promovida pelos "aglomerados" grupo composto por estudantes de distintos cursos da UFSM. A música seria de responsabilidade de $D J s$, da banda "Pimenta e seus comparsas" e o grupo "Gurizada Fandangueira" 14.

Nesta madrugada, por volta das $2 \mathrm{~h} 30 \mathrm{~min}$ o grupo Gurizada Fandangueira apresentavase, e em determinado momento do show, utilizou-se de um artefato pirotécnico como elemento

\footnotetext{
10 IBGE, Santa Maria, disponível em < https://www.ibge.gov.br/estatisticas-novoportal/por-cidade-estado-estatisticas.html?t=destaques\&c=4316907>. Acessado em 15 de novembro de 2018

11 UFSM em Números, disponível em https://portal.ufsm.br/ufsm-em-numeros/publico/index.html. Acessado em 15 de novembro de 2018

12 UFN em Dados, disponível em http://www.ufn.edu.br/site/institucional. Acessado em 15 de novembro de 2018.

13 Diário de Santa Maria, 28 de janeiro de 2013, p. 20-21.

14 Segundo o banner da festa (2013), disponível em http://g1.globo.com/rs/rio-grande-do-sul/noticia/2013/01/festa-que-acabou-em-tragedia-reunia-universitariosem-santa-maria.html. Acessado em 15 de novembro de 2018.
} 
compositivo da performance, sendo esta a fonte de ignição para a queima do material que revestia teto e parede da boate, utilizado como isolante acústico, erroneamente, sendo comprovado a causa da morte por asfixia pelos gases emitidos pela queima do mesmo.

Somado a isto, a estrutura da casa de shows, como os entraves, barra corpos, labirintos, falta de extintores de incêndio ou mesmo iluminação de emergência, e a falta de preparação e comunicação com e entre os funcionários foram igualmente responsáveis pela situação em que padeceram os jovens naquela noite.

Desta forma, nos momentos que se seguiram, muitas vítimas não conseguiram escapar das dependências do prédio, fazendo com que alguns daqueles que saíram e que recobraram sua consciência voltassem ao interior da Kiss para tentar salvar alguém. Com o mesmo intuito um grupo de rapazes brevemente começou a quebrar a fachada visando resgatar alguém, ou mesmo prover a circulação de ar no espaço.

$\mathrm{Na}$ sequência dos fatos, muitos foram os envolvidos e grande foi a movimentação da cidade, região, do país ou mesmo estrangeira, já relatados em documentários e livros, como o “Todo dia a mesma noite" de Daniela Arbex (2018).

$\mathrm{O}$ que nos resta afirmar quanto a boate Kiss e que tem total relação com as disputas empreendidas de 2013 até a atualidade, são resultado das militâncias das famílias em busca da justiça pelas mortes de seus entes. Por sua vez, o Inquérito Policia $n^{\circ} .:$ 001/2013 da $3^{\circ}$ Delegacia Regional da Polícia Civil do Estado do Rio Grande do Sul, em que por meio de relatório datado de 2014, levanta diversas investigações referentes às ilegalidades praticadas pela Santo Entretenimento Ltda no que dizia respeito a criação e mesmo o funcionamento do espaço. Nesse sentido, fornecendo provas e argumentos legais para a posição de resistência perante o Estado. Este documento discute a emissão de alvarás, a assinatura de abaixo assinados, a relação dos vizinhos com os sócios e os relatos a respeito do funcionamento da casa. As acusações nele contidas ecoam nas vozes dos familiares das vítimas fatais e nos sobreviventes até hoje, solicitando a responsabilização dos agentes públicos e membros da sociedade civil ligados a boate, os seus administradores e sócios.

Nos dias que se seguiram ao acontecimento a sociedade santa-mariense movimenta-se com força. Iniciados pela corrida dos hospitais em busca dos sobreviventes, a estruturação de atendimento psicológico para os envolvidos, a cortesia daqueles que estendiam a mão para ajudar os necessitados, a missa de sétimo dia e as discussões que dão início a conformação de associações de familiares de vítimas, como a Associação de familiares de vítimas e sobreviventes da tragédia de Santa Maria (AVTSM) criada em 22 de fevereiro de 2013 com o 
apoio da defensoria público de Santa Maria ${ }^{15}$. Tal estrutura compõe-se pelo protagonismo de familiares das vítimas, por meio de um Conselho Diretor composto por Presidente, Vicepresidente, $1^{\mathrm{a}}$ Secretária, $2^{\circ}$ Secretário, $1^{\circ}$ Tesoureiro, $2^{\circ}$ Tesoureiro, Diretor de Ação Social, Diretor de Comunicação Social, Diretor de Assuntos Jurídicos; Conselho Fiscal; e Conselho Administrativo 16 .

A partir da criação da AVTSM, diversas são as frentes em que os familiares atuam de maneira organizada, divididos em frentes de Ação Social, Comunicação Social e Assuntos Jurídicos. Neste sentido, como uma das ações cria-se em abril de 2013 a Tenda da Vigília que discutiremos na sequência.

\section{Espaço de resistência Tenda da Vigília}

Conforme enunciado, o espaço denominado como Tenda da Vigília surge poucos meses após o incêndio na boate Kiss, tendo como integrantes dessa criação os familiares membros da AVTSM. Localizada na Praça Saldanha Marinho, ao lado do viaduto Evandro Behr, a frente da Agência do Banrisul e cerca do Calçadão representa e apresenta uma marcação no território, constituída conforme anuncia Fabri, como "un lugar inserto y constituido a partir de una trama particular de poder" (2013). Assim, os sujeitos envolvidos adentram a categoria de "hacedores de cidade" conforme Vecchiolli (2014), em que estes imprimem naquele local a marca da memória. Composta por uma lona fixada em estrutura quadrada de metal de aproximadamente $4 \times 4$ a tenda é composta por um banner que faz menção às 242 vítimas, com suas fotografias e nomes, com exceção daqueles que as famílias não cederam autorização para veiculação da imagem dos filhos, estes sendo representados por uma estrela e somente com as iniciais dos nomes. Ainda, são organizados por ordem alfabética, e a cada encontro estrutura móvel é montada e desmontada, composta por cadeiras de praia, duas mesas, uma para a imagem de Nossa Senhora, livro de visitas e expor outras coisas e outra para uso dos participantes.

15 Criação da AVTSM (2013), disponível em http://www.defensoria.rs.def.br/conteudo/1533. Acessado em 15 de novembro de 2018.

16 AVTSM, CliksRBS (2013), disponível em http://www.clicrbs.com.br/especial/jsp/default.jspx?uf=1\&local=1\&espid=165\&action=noticias\&id=4056723. 


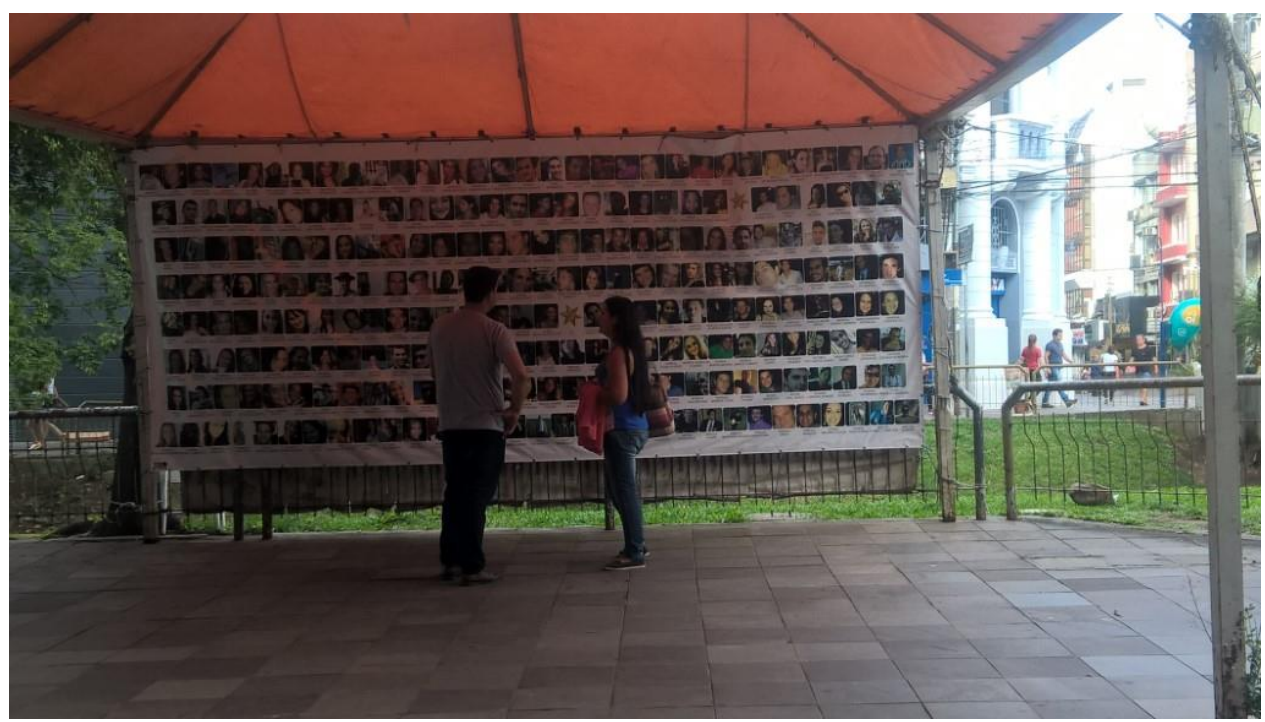

Figura 4: Tenda da vigília, com banner das fotografias das vítimas.

Fonte: Autores

Em seu início os integrantes propunham a existência do espaço durante 242 dias, em que seriam realizadas vigílias diárias dedicadas a cada vítima fatal do incêndio. Contudo, após o término deste prazo, os familiares decidiram continuar a empreender as vigílias, que com o passar do tempo foram diminuindo de frequência, até chegar ao momento atual em que são realizadas uma vez por semana, às quartas-feiras das $9 \mathrm{~h}$ às $17 \mathrm{~h}$ e todo dia 27 de cada mês.

Nestas conformações contemporâneas, a tenda tornou-se um espaço de múltiplas características e possibilidades. Inclusive por conta da passagem da gestão da AVTSM para o Movimento SM do Luto à Luta, no início de $2014^{17}$. Assim, conforma-se como um espaço de rememorar e de homenagear as vítimas, mas também um espaço de resistência contra as forças do esquecimento. Além disso, a partir de diversas ações envolve a comunidade santa-mariense, seja por meio dos eventos realizados como a festa das crianças, e outros, ou mesmo as arrecadações de materiais escolares a serem doados a comunidades carentes, e como cerne o ato de tecer, dado por meio dos quadradinhos de amor. Material e prática adotada pelas mães para congregar seus encontros e promover a caridade a recém-nascidos nos hospitais da cidade.

Por meio de diversas ações, sobretudo as mães, mantêm viva a memória de suas filhas e filhos, nestes contar, neste tecer, naquele espaço em que se realizam orações, minutos de barulho, que reúne banners e histórias de seus entes. Assim a tenda da vigília representa o que há de mais vivo na memória destas pessoas, e configura-se como proposta singular por estes motivos.

\footnotetext{
17 Diário de Santa Maria, Movimento do Luto à Luta é o novo responsável pela tenda no Calçadão de Santa Maria (2014), disponível em, https://diariosm.com.br/not\%C3\%ADcias/geral/movimento-do-luto-\%C3\%A0-luta-\%C3\%A9-o-novo-respons\%C3\%A1vel-pela-tenda-no-cal\%C3\%. Acessado em 15 de novembro de 2018.
} 


\section{Memorial às Vítimas da Boate Kiss}

Outra iniciativa de memória protagonizada pelos familiares dá-se através da proposição de construção de um Memorial às Vítimas da Boate Kiss no local em que aconteceu a barbárie. Desta forma, meses após o incêndio a AVTSM demonstra seu desejo em construir um memorial no local e ao mesmo tempo recebe propostas de projetos para este, como é o caso da proposta apresentada pelo artista visual gaúcho Mauro Pozzobonelli em meados de abril de $2013^{17}$, e que teria sido aprovado pela primeira gestão da AVTSM, mas que, conforme afirma o presidente fundador em sua saída do cargo (2015), “[...]houve divergência no grupo, pisei no freio e não consegui efetivar. [...] Queria ter feito. O que não pode é aquele prédio ficar um mausoléu. Tem que ser feito algo ali.",18

Assim mesmo, com o ingresso da nova direção o tema não cai em esquecimento, demonstrado pelas articulações realizadas com o poder público visando a desapropriação do prédio que sediou a boate, resultando no decreto executivo 72/2016 assinado em 6 de setembro de 2016, que considera o terreno de interesse público, com vistas à desapropriação do mesmo para futuras intervenções ligada a memória, a vida e a juventude, para que a tragédia nunca mais aconteça.

Por isso, já em 2017 a AVTSM articula com o Instituto de Arquitetos do Brasil e comunidade as possibilidades de criação de um memorial, e lança uma campanha de arrecadação financeira coletiva para custear o concurso que seria responsável por eleger o projeto a ser construído no local ${ }^{19}$. Desta forma, após alguns meses de campanha de arrecadação em janeiro de 2018 é lançado o Concurso Nacional de Projetos Arquitetônicos para o Memorial às Vítimas da Boate Kiss, em parceria da AVTSM com o IAB-RS, o qual tem seu resultado divulgado em abril, tendo como ganhador um projeto submetido por escritório da cidade de São Paulo.

\footnotetext{
18 Jornal do Brasil, Memorial vai lembrar tragédia na Boate Kiss (2013), disponível em, http://www.jb.com.br/pais/noticias/2013/05/25/memorial-vai-lembrartragedia-na-boate-kiss/. Acessado em 3 de maio de 2018.

19 Diário de Santa Maria, 27 de janeiro de 2015, P. 8-9

G1, Comunidade e autoridades discutem memorial em homenagem às vítimas da boate Kiss (2017), disponível em https://g1.globo.com/rs/rio-grande-dosul/noticia/comunidade-e-autoridades-discutem-memorial-em-homenagem-as-vitimas-da-boate-kiss.ghtml. Acessado em 3 de fevereiro de 2018.
} 


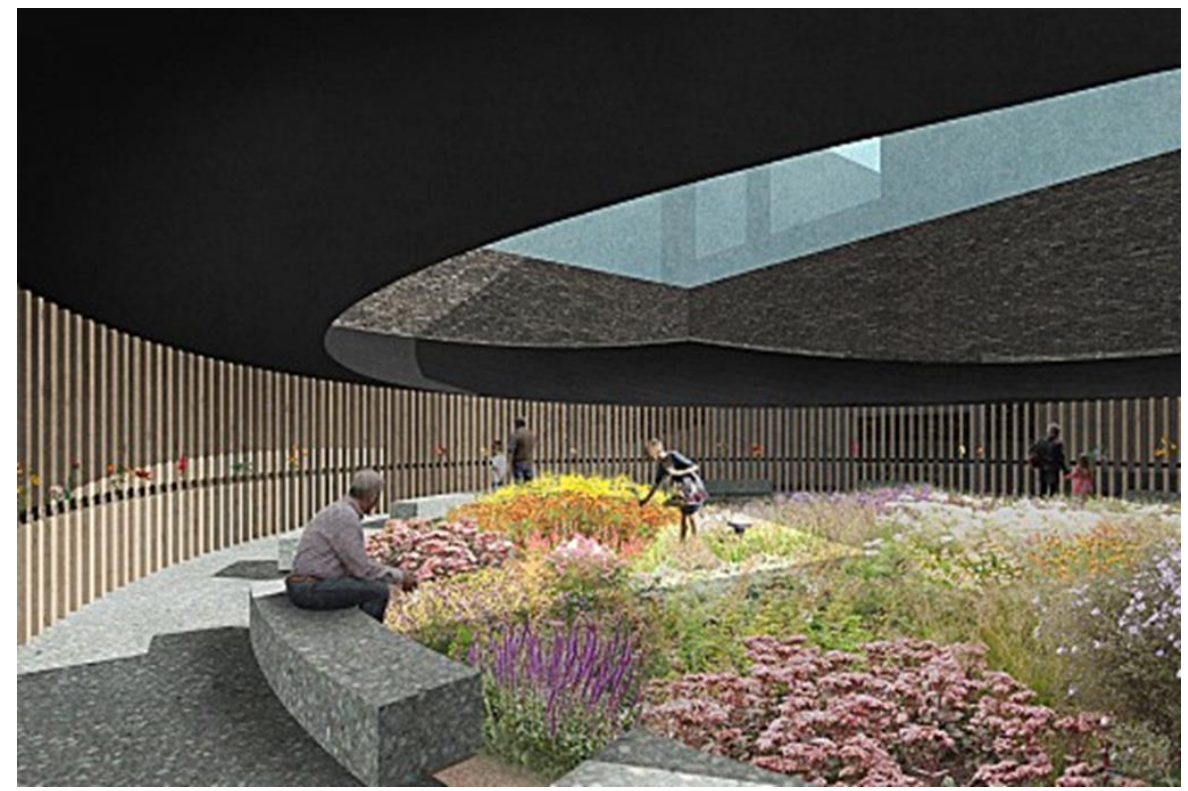

Figura 5: Projeto Arquitetônico Memorial às Vítimas da Boate Kiss. Jardim Central.

Fonte: Concurso público nacional de arquitetura para o Memorial às Vítimas da Kiss. ${ }^{20}$

Assim, durante o ano de 2018 vem realizando-se ajustes e complementações ao projeto eleito, visando com que até o final do ano estejam todos prontos para que se dê início às atividades de captação de recursos, via arrecadação coletiva, leis de fomento à cultura, editais e outros. Ainda, há a necessidade de resolução dos processos jurídicos em andamento para que o prédio, instituído como parte do processo possa ser então demolido, viabilizando a construção do memorial.

\section{Os três casos, apropriações, distanciamentos e aproximações}

Compreendemos que as iniciativas memoriais citadas, conforme apresentamos surgem a partir de contextos diversos, sejam estes em épocas, locais e a partir de protagonismos distintos. Desta forma, integrando parte do fenômeno que definem Bezerra e Serres como

[...] um novo campo de ação patrimonial dedicado à compreensão das memórias difíceis, pois os efeitos destas novas formas de comemoração do passado, ainda não estão claras e, tampouco existe um consenso no que diz respeito aos métodos experimentados pelos meios de transmissão destas novas memórias. (BEZZERA E SERRES, 2015, p. 175)

Assim, estes espaços podem ser analisados conforme o conceito amplamente discutido por Pierre Nora (1993), dos lugares de memória, encontrando nas palavras de Régine Robin

20 Disponível em: https://concursos.arqs.com.br/concursomemorial/resultado/01_657735/ Acessado em 15 de novembro de 2018. 
(2014), a busca a respeito da constituição de espaços memoriais instalados em 'sítios autênticos', como campos de concentração nazistas e palcos de tragédias. E por outro lado, aqueles construídos em outros espaços, os denominados 'lugares de memória', que recebem marcas memoriais e que recebem a memória, não estando necessariamente vinculados ao local físico do acontecimento.

Por isso, estes locais, marcados pela dor ou que são eleitos para receber ações de representação desta, dão lugar a manifestações públicas, como menciona Ferreira (2017), com respeito ao local do atentado a bomba na estação de metrô madrilenha, Atocha, ocorrido em 2004, em que algumas horas após o espaço começava a receber velas e flores dedicadas a homenagear as vítimas.

Estas ações integram o que Tornatore define como 'proliferação' da memória, para além do 'mnetropismo' de Candau (2010), sendo como uma possibilidade de democratização da memória, a partir de um movimento em que não só mais o Estado cumpre o papel de patrimonializar, dando lugar a pequenos grupos na seara da patrimonialização (2010).

No caso de São Paulo, referente ao Memorial 17 de julho, recorremos ao pensamento de Regine Robin, quando defende que estes espaços,

Despliegan su propia memoria, a menudo sin rastros, a veces por medio de huellas más o menos legibles, ya sea se encuentren abandonados o, por el contrario, se los conserve. (ROBIN, 2014, P. 125)

O citado memorial como apresentado na discussão foi criado pela ação de diversos agentes vinculados ou não ao poder público municipal, como pais e outros familiares das vítimas. Assim mesmo, atualmente, o espaço de memória apresenta claros sinais de abandono estrutural ou mesmo de circulação de pessoas. Logo, indaga-se a respeito da sua capacidade de transmissão e ação entre os sujeitos que ali circulam. Reforçamos que este e os outros espaços tem outras missões a partir de diversas leituras, como a dos familiares que o enxergam como homenagem e/ou forma de não esquecimento. Contudo, como ferramenta de transmissão da memória do que ali aconteceu, acreditamos que para agentes externos a situação seja uma difícil missão.

Nesse sentido, acredita-se que a constituição de marcos memoriais deve estar alicerçada com ideias que propiciem, antes mesmo da construção do espaço usos e funções dinâmicas, como vem sendo proposto no caso do Memorial às vítimas da boate Kiss. Certamente, não será possível dizer que a forma de ação de um espaço é mais acertada que outro, uma vez que temos consciência de diversos fatores que influenciam em seus casos. Por isso, somente podemos 
afirmar que é necessário ter como objetivo a manutenção e continuidade das ações desde o início dos projetos.

Ainda em se tratando do caso de Santa Maria, os memoriais dedicados às vítimas surgem ou são desenvolvidos por diversos agentes em parceria com os familiares pertencentes a Associação de Familiares das Vítimas da Tragédia de Santa Maria. Sendo o memorial a ser construído no local da boate, fruto de relação com diversos expertos e poder público municipal, assim como o Memorial Tenda da vigília. Já o Memorial a Vida na Universidade Federal de Santa Maria recebe maior contribuição dos servidores públicos vinculados a ela das mais diversas áreas, sempre em conjunto com os familiares. Nesse sentido, o caso de Santa Maria, repercute em diversas esferas, sobretudo por conta da participação de múltiplos agentes a elas vinculados.

Em se tratando do Memorial da Resistência, indagamo-nos com que propósito o Memorial da Resistência de São Paulo surge como uma referência para ditadura no Brasil? É necessário um contexto de criação, que não tenha somente o reconhecimento apenas do estado de São Paulo, mas sim dentro de um contexto de transição e busca de justiça de familiares e vítimas de todos os brasileiros. Com este argumento, $\operatorname{Neves}^{21}$ (2011) defende que o Museu da Resistência de São Paulo, é o resultado de três elementos que são: a reivindicação da comunidade, o interesse do governo e a intervenção museológica. A iniciativa da organização do Memorial da Resistência é proveniente da sociedade civil, e deve ser reconhecida e tratada com verdade, não meramente como uma experiência pedagógica para compreender a ditadura militar no estado de São Paulo, mas como um espaço para conhecimento e formação da memória de eventos trágicos.

As atividades de implantação do Memorial da Resistência como citado anteriormente, foram iniciadas em maio de 2008, segundo Neves (2011) “quando também foi inaugurada a exposição "Direito à Memória e à Verdade. A ditadura no Brasil (1964 - 1985)", e foram iniciadas as atividades com o Fórum Permanente de ex-Presos e Perseguidos Políticos do Estado de São Paulo e as tratativas burocráticas para a contratação da equipe técnica". Neste sentido as vítimas da ditadura militar participam ativamente da construção das narrativas do local e das atividades desenvolvidas dentro da instituição, uma vez que a coleta de testemunhos, foi necessária para o entendimento do cotidiano na prisão, e do espaço carcerário.

Foram realizadas quatro sessões de coletas de testemunhos, em que participaram militantes de distintas organizações políticas (Partido Comunista do Brasil, Ação Libertadora Nacional, Ação Popular etc.) e ocupações (estudante, educador, operário,

21 Dissertação de mestrado intitulada "A potencialidade dos lugares de memória sob uma perspectiva museológica processual: um estudo de caso. O Memorial da Resistência de São Paulo". 
gráfico, jornalistas e ferroviário): Ivan Seixas, Maurice Politi e Alípio Freire; Elza Lobo e Rose Nogueira; Raphael Martinelli e José Paiva; e Frei Betto, sempre acompanhadas pelos representantes do Fórum, que atuaram como mediadores, e pela equipe de implantação (NEVES, 2011, p. 94)

A participação das vítimas na construção deste "lugar de memória" foi de extrema importância, uma vez que os ex-Presos participaram do processo de construção do projeto expográfico, Neves (2011) conta que:

A participação dos ex-presos foi muito mais ampla no período que antecedeu a inauguração do Memorial da Resistência, quando pudemos contar com parceiros de fato, que trabalharam em vários segmentos com a equipe e colaboraram empenhadamente para a resolução dos inúmeros desafios: na ambientação da cela 3 , na gravação em estúdio para o áudio da cela 4 , na cessão de documentos e fotografias para os recursos expográficos, no atendimento em visitas educativas e realização das atividades culturais (os Sábados Resistentes), na articulação com instâncias governamentais, entre tantas outras formas de companheirismo ((NEVES, 2011, p. 98)

O Memorial da Resistência de São Paulo, está aberto a receber as denúncias e relatos das vítimas da ditadura no Brasil, os testemunhos das vítimas são elementos essenciais para a resistência, justiça de transição e direitos humanos.

Nesse sentido, entendemos que estes espaços devem fazer ver as conformações que anteriores que neles resultam, como defende Vecchiolli, quando diz que memoriais, citando um caso porteño, são fruto de

[...] batallas simbólicas acerca del sentido de la memoria, el olvido y la recuperación $\mathrm{y}$, en última instancia, disputas por el poder de decir cómo debe construirse el espacio público y quiénes son los actores legítimos para hacerlo. (VECCHIOLLI, 2014, p. 11)

Bem como Cymbalista, quando se refere aos papéis que desempenham estes espaços, entendendo-os como

[...] catalisadores de narrativas, são repositórios de esperanças e de identidades. São lugares que adquirem uma dimensão política - e por isso mesmo, possuem potencialidades pedagógicas. [CYMBALISTA, 2017. P. 33]

Por fim, acreditamos que estes espaços criados para vítimas, possuem suas peculiaridades, por vezes no seu contexto de criação e na forma como são gerenciados. Nos interessa saber quem são os atores e quais são as apropriações em processo. Nota-se que o Memorial da Resistência de São Paulo por ser gerenciado pela Pinacoteca de São Paulo, desfruta de cuidados para a eficácia do funcionamento, além de estar em constante contato com vítimas e atores. Enquanto o seu vizinho, 17 de julho depende da prefeitura de São Paulo para a manutenção do espaço, e que os casos de Santa Maria dividem-se em gestão.

\section{Referências}


ARBEX, D. Todo dia a mesma noite. Rio de Janeiro: Intrinseca, 2018. 240 p. (Obra completa)

BRITO, A. P. F. O tempo da memória política: (re) significando os usos sobre a memória do período militar no Brasil. 2014. 190 f. Dissertação (Mestrado em Memória Social e Patrimônio Cultural) - Instituto de Ciências Humanas. Universidade Federal de Pelotas. 2014. (Dissertação)

BEZERRA, D. B; SERRES, J. C. P. A estetização política dos lugares de memória. Revista história, histórias, vol. 3, n. 6, p. 173-188, 2015. Disponível em: http://periodicos.unb.br/index.php/hh/issue/view/749/Edi\%C3\%A7\%C3\%A3o\%20Completa_ v.3\%2C\%20n.\%206\%20\%282015\%29. Acesso em: 15 nov. 2018. (Artigo em Periódico Digital)

CANDAU, J. Bases Antropológicas e Expressões Mundanas da Busca Patrimonial. Memória, Tradição e Identidade. Revista Memória em rede, v. 01, n. 01, p. 37-52, 2009/2010. Disponível em: https://periodicos.ufpel.edu.br/ojs2/index.php/Memoria/article/view/9564. Acesso em: 15 nov. 2018. (Artigo em Periódico Digital)

COMANDO DA AERONÁUTICA. Relatório do Centro de Investigação e Prevenção de Acidentes Aeronáuticos, A - no 67 2009. Brasília, 2009. 300p. (Obra completa)

CONCURSO PÚBLICO NACIONAL DE ARQUITETURA PARA O MEMORIAL ÀS VÍTIMAS DA KISS. Projeto Arquitetônico Memorial às Vítimas da Boate Kiss, Jardim Central. Abr. 2018. Disponível em: https://concursos.arqs.com.br/concursomemorial/resultado/01_657735/ Acesso em 12 nov. 2018. (Site)

CYMBALISTA, R. Mobilizações da Memória em lugares de morte em são Paulo: Flavio Sant'anna, Edson Neris, Andrea de Mayo. Revista do centro de pesquisa e formação, $\mathrm{n}^{\circ}$ 5, $\mathrm{p}$. 22-37 set. 2017. Disponível em: https://www.sescsp.org.br/online/revistas/edicoes/678_REVISTA+DO+CENTRO+DE+PESQ UISA+E+FORMACAO+N05+ISSN+24482773. Acesso em: 18 nov. 2018. (Artigo em Periódico Digital)

ESTADO DO RIO GRANDE DO SUL; POLÍCIA CIVIL; $3^{a}$ DELEGACIA DE POLÍCIA REGIONAL. Inquérito Policial $n^{\circ}$ : 001/2013/3a . Santa Maria, 2013. 253p. (Obra completa)

FERRAZ, A. Luto e alerta marcam homenagem às vítimas do voo da TAM. In: O Estado de São Paulo. 17 de julho de 2012. Disponível em: $<$ https://brasil.estadao.com.br/noticias/geral,luto-e-alerta-marcam-homenagem-as-vitimas-dovoo-da-tam,901598 Acessado em novembro de 2018. Acessado em 10 nov. 2018. (Artigo em Periódico Digital)

FABRI, S. M. Lugares de memoria y marcaciones territorial: sobre la recuperación de los centros de detencion en Argentina y los lugares de memoria en España. Revista Colombiana Cuadernos de Geografia, v. 22, n. ${ }^{\circ}$ 1, p. 93-108, ene.-jun. 2013. Disponível em: https://revistas.unal.edu.co/index.php/rcg/article/view/36307/37941. Acesso em: 10 nov. 2018. (Artigo em Periódico Digital)

FERREIRA, M. L. M. Memória, paz e reconciliação: entrevista com Camilo Posso. Revista Memória em Rede, v.9, n.17, p. 162-176, jul./dez.2017. Disponível em: 
https://periodicos.ufpel.edu.br/ojs2/index.php/Memoria/article/view/11385. Acesso em: 10 nov. 2018. (Artigo em Periódico Digital)

FÓRUM PERMANENTE DOS EX-PRESOS E PERSEGUIDOS POLÍTICOS DO ESTADO DE SÃO PAULO. Disponível em: https://forumexpresospoliticossp.wordpress.com. Acesso em: 20 de novembro de 2018. (Site)

Reformulação do estatuto do fórum dos ex-presos e perseguidos políticos do Estado de São Paulo. São Paulo. mar. 2013. Disponível em: https://forumexpresospoliticossp.files.wordpress.com/2013/08/reformuac3a7c3a3o_estatuto_f c3b3rum.pdf . Acesso em: 14 de janeiro de 2019. (Obra completa)

MEMORIAL DA RESISTÊNCIA DE SÃO PAULO. Disponível em: http://memorialdaresistenciasp.org.br . Acesso em: 25 de outubro de 2018. (Site)

NEVES, K. R. F. A potencialidade dos lugares de memória sob uma perspectiva museológica processual: um estudo de caso. O Memorial da Resistência de São Paulo. 2011. 182 f. Dissertação. (Mestrado em Socio-Museologia) - Universidade Lusófona de Humanidades e Tecnologia Faculdade de Ciências Sociais e Humanas - Departamento de Museologia. Lisboa. 2011. (Dissertação)

NORA. P. Entre a memória e a história a problemática dos lugares. Revista Projeto História, São Paulo, no10, dez. 1993. Disponível em: https://revistas.pucsp.br/index.php/revph/article/view/12101. Acesso em: 15 nov. 2018. (Artigo em Periódico Digital)

POLLAK. Memória, Esquecimento, Silêncio. Revista Estudos Históricos, v. 2, n. 3, p. 3-15, 1989. Disponível em: http://bibliotecadigital.fgv.br/ojs/index.php/reh/article/view/2278. Acesso em:: 12 nov. 2018. (Artigo em Periódico Digital)

ROBIN, R. Sitios de memoria y intercambios de lugares. Revista Interdisciplinaria de Estudos Sobre Memoria, $\mathrm{n}^{\mathrm{o}}$ 2, p. 122-145, Oct. 2014. Disponível em: http://ppct.caicyt.gov.ar/index.php/clepsidra/article/view/Robin/pdf. Acesso em 11 nov. 2018. (Artigo em Periódico Digital)

SERRES, J. C. P.; FERREIRA, M. L. M. A difícil memória: Musealização do hospital colônia de Itapuã, RS, Brasil. Revista Cadernos de Sociomuseologia, no 5, p. 61-87, 2015. Disponível em: http://revistas.ulusofona.pt/index.php/cadernosociomuseologia/article/view/5226/0. Acesso em: 18 nov. 2018. (Artigo em Periódico Digital)

TORNATORE, J-L. Patrimônio, memória, tradição, etc: discussão de algumas situações francesas da relação com o passado. Revista Memória em Rede, v. 1, n. 1, p. 7-21, 2010. Disponível em: https://periodicos.ufpel.edu.br/ojs2/index.php/Memoria/article/view/9562. Acesso em: 15 nov. 2018. (Artigo em Periódico Digital)

VECCHIOLI, V. La monumentalización de la ciudad: los sitios de memoria como espacios de intervención experta de los hacedores de ciudad. Revista estudios sociales contemporáneos, $\mathrm{n}^{\circ}$ 10, p. 33-44, jul. 2014. Disponível em: http://bdigital.uncu.edu.ar/app/navegador/?idobjeto=6429. Acesso em 15 nov. 2018. 